$X$-ray films are of most help in the diagnosis of tuberculosis when they show clear-cut evidence of miliary mottling or gross enlargement of hilar or paratracheal nodes. Perihilar inflammatory changes are sometimes reported, and may be similar to those seen in acute bacterial infections or in measles, so that the significance of a single $x$-ray film is often doubtful. If $x$-ray examinations can be repeated after a trial of antibiotics their value is considerably enhanced. In the present study $x$-ray films were diagnostic of tuberculosis in $50 \%$ of the patients. In 16 of the tuberculin-negative children the radiological features alone were thought to justify antituberculous treatment.

This work was supported by a grant from the East African Medical Research Council. I am indebted to Mr. J. K. Clancey, M.R.C. Bacteriologist, and to his department for undertaking the bacteriological investigations. I am grateful to the paediatricians at
Mulago Hospital for permission to investigate patients with malnutrition under their care, and to Professor R. A. McCance, of the M.R.C. Infantile Malnutrition Research Unit, for his advice and help in the preparation of this paper.

\section{REFERENCES}

Bentzon, J. W. (1953). Tubercle (Lond.), 34, 34

Brown, R. E. (1965). Trop. geogr. Med., 17, 189.

Grounds, G. (1962). E Atr. med. 7., 39, 577 .

Grounds, P. G. E G. and Brown, R. E. (1965). E. Afr. med. 7., 42, 233. Harland, P. S. E. G. (1965). Lancet, 2, 719.

Harland, P. S. E. G. (1965). Lancet, 2, 719. 140

Lloyd, A. V. C. (1968). E. Afr. med. F., 45, 140. (1963). Tuberculosis in Children. London.

Rich, A. R. (1951). The Pathogenesis of Tuberculosis, 2ad ed. Springfield, Illinois.

Satge, P., Charreau, M. Boal, E., Laffont, M., and Blatt, M. (1965), Méd. Afr. noire, 12, 169.

Whitehead, R. G., and Dean, R. F. A. (1964). Amer. F. clin. Nutr., 14, 320 .

\title{
Double-blind Controlled Trial of a Micronized Preparation of Flumedroxone (Demigran) in Prophylaxis of Migraine
}

\author{
W. G. BRADLEY,* M.A., B.M., B.SC., M.R.C.P. ; P. HUDGSON, $\dagger$ M.B., M.R.A.C.P. ; J B. FOSTER, $\ddagger$ M.B., M.R.C.P. \\ D. J. NEWELL, $§$ M.A., PH.D.
}

Brit. med.F., 1968, 3, 531-533

\begin{abstract}
Cummary : A double-blind cross-over trial of a micronized preparation of flumedroxone, an oral progestogen derivative, and a placebo was undertaken to determine whether this drug had prophylactic value in migraine. No benefit was found in males, or in females with no history of menstrual exacerbation of migraine. In women whose migraine was worse around the time of menstruation flumedroxone resulted in statistically fewer headaches of less severity.

With the dose used in this trial (micronized flumedroxone $10 \mathrm{mg}$. t.d.s.) side-effects were frequent, the commonest being polymenorrhagia, which occurred in half the women of reproductive age.
\end{abstract}

\section{Introduction}

In an earlier controlled trial performed at this centre (Hudgson et al., 1967a) it was shown that methysergide $1 \mathrm{mg}$. t.d.s. produced a significantly greater reduction in the frequency of migrainous headaches than did flumedroxone $5 \mathrm{mg}$. t.d.s. The latter is a modified oral progestogen, and was claimed to have no progestational or metabolic effects on the human (Sørensen, 1964). Methysergide had previously been shown to be an effective prophylactic against migraine (Southwell et al., 1964 ; Whewell, 1966). However, methysergide is well known to cause retroperitoneal fibrosis (Schwartz et al., 1966), particularly when taken for long periods at high dosage, as well as unpleasant though insignificant side-effects, including nausea, vomiting, and giddiness, in some patients. Moreover, recent experience strongly suggests that methysergide can also cause acute myocardial infarction (Hudgson et al., 1967b, 1967c).

* Clinical and Research Fellow in Neurology.

† Senior Research Associate in Neurology. Present appointment: First Assistant in Neurology, Royal Victoria Infirmary, Newcastle upon Tyne.

$\ddagger$ Consultant Neurologist.

Professor of Medical Statistics.

Regional Neurological Centre, Newcastle General Hospital, and the Nuffield Department of Industrial Health, the University of Newcastle upon Tyne.
In view of these dangers methysergide must be used with great caution in the prophylaxis of such a benign and chronic condition as migraine, and it was decided to look again at the effectiveness of flumedroxone, this time comparing it with a placebo. In the meantime a micronized preparation of flumedroxone has been developed which increases absorption about fifteenfold compared with the previous product tested by us. In addition, double the dose of flumedroxone was used in the present trial $(10 \mathrm{mg}$. t.d.s.), so that the effective absorbed dose was increased about thirtyfold compared with the previous trial. It was anticipated that polymenorrhagia-that is, excessively frequent and excessively heavy menstrual periodsencountered in a third of the women of reproductive age in our previous study, and also reported by Lundberg (1965), might be a limiting factor in the usefulness of this drug.

\section{Material and Methods}

Forty-eight patients suffering more than one typical migrainous headache a month requested therapy to reduce the frequency of their headaches. Fifteen were men and 33 women. One man failed to attend after the first interview, having been given the active drug for the first month; four women similarly failed to come more than once, all having been given placebo for the first month. Two additional women failed to complete the trial, one having had the active drug for three months and the placebo for two months and the other three months with the placebo and one month with the active preparation. Two women had to be withdrawn because of severe side-effects (see below).

Thus 14 men and 25 women completed the trial. Eighteen women gave a history of migrainous headaches which were more frequent around the time of menstruation, and these and the remaining seven women with no such history have been analysed separately. Most of the patients were under 40 years,

1 The placebo contained maize starch, lactose, talc, magnesium stearate, gelatin, and sorbitol. 
though age was no barrier to inclusion in the trial. Three of the men suffered from periodic migrainous neuralgia.

Allocation of Patients to Treatment Groups.-The trial was a double-blind cross-over study, each patient receiving three months' treatment with micronized flumedroxone $10 \mathrm{mg}$. t.d.s. and three months with an indistinguishable placebo, ${ }^{1}$ the two periods being separated by a month with no specific therapy. Whether the patient received the active preparation or the placebo first was decided by a table of random numbers, which was kept, together with the code, by the hospital group pharmacist. Eighteen patients received placebo first, and 21 the active preparation first. Neither the physician nor the patients knew the nature of the medication for each period until the completion of the trial by each patient.

Follow-up Interviews-Each patient was given a daily diary and recorded the duration and severity of each headache as well as other symptoms. The severity was scored as three for severe, two for moderate, and one for mild. Patients were seen monthly, and the total number of headaches, total duration, and summated severity scores were recorded for each three months' treatment. The blood pressure and weight were recorded at the beginning of the trial and at the end of each three-month treatment period; changes from the pretreatment level were recorded. At the end of the trial the patient was asked to express a preference for one or other treatment period.

\section{Males}

\section{Results}

The number of headaches suffered by each man during each treatment period was recorded (see Table) and the difference between them used as a measure of the effectiveness of the drug. Of the 14 patients nine had more headaches on the active drug, four had fewer, and one had the same number on drug and placebo. The Wilcoxon matched-pairs signed-rank test, which takes some account of the magnitude as well as the direction of change, was applied to these differences and the result was not significant.

Results in Males, and in Females with Menstrual Exacerbation

\begin{tabular}{|c|c|c|c|c|}
\hline & \multicolumn{2}{|c|}{ Males } & \multicolumn{2}{|c|}{ Females } \\
\hline & Active & Placebo & Active & Placebo \\
\hline 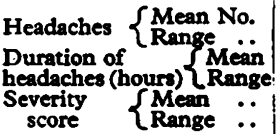 & $\begin{array}{c}33 \\
2-94 \\
67 \\
1-1,160 \\
21 \cdot 5 \\
2-169\end{array}$ & $\begin{array}{l}30 \\
1-108 \\
40 \\
1-589 \\
24 \cdot 5 \\
1-154\end{array}$ & $\begin{array}{c}14 \\
3-56 \\
270 \\
28-620 \\
31 \\
8-101\end{array}$ & $\begin{array}{c}17 \\
1-55 \\
245 \\
47-463 \\
37 \\
2-116\end{array}$ \\
\hline
\end{tabular}

The total duration of headaches for each patient was also recorded for each of the treatment periods. The severity of headaches score was not significantly different in the two treatment periods. Nine patients had more severe headaches on the active drug, four had more severe headaches on the placebo, and one felt the same on both active and placebo.

There was no significant difference in blood pressure or weight between the two treatment periods. Blood pressure recordings were lower on the active drug in six patients and higher in one. In three the blood pressure was the same during both treatments and for four patients it was not recorded. Weight was down in four patients while taking the active drug, up in three, the same in three, and four were not weighed.

There were no statistically significant preference by the patients for the active drug or placebo, five preferring the active drug, four the placebo, and five having no particular preference.

\section{Females with Menstrual Exacerbation}

The number of headaches suffered by each patient during each treatment period was recorded (see Table) and the differ- ence between them used as a measure of the effectiveness of the drug. Six out of the 18 patients had more headaches while taking the drug, 11 had more while taking the placebo, and one had the same on both. The Wilcoxon matched-pairs signed-rank test was applied to these differences and showed that when taking the active drug the patients suffered significantly fewer headaches $(P<0.05)$.

Duration of headaches was noted for each patient for the two treatment periods. Nine had headaches of longer duration on the active drug and nine suffered longer on the placebo. The Wilcoxon test took account of the magnitude of the duration and showed there was no significant difference between drug and placebo.

The headache severity scores for the two treatment periods showed that 6 of the 18 patients experienced headaches of greater severity when taking the active drug, 11 had worse headaches when taking the placebo, and one felt the same on both. The Wilcoxon test shows that the placebo was significantly worse than the active drug $(P<0.05)$.

Blood pressure was up in four patients while on the active drug, up in six patients while on the placebo, and was the same on both drug and placebo in one patient. It was not recorded in the other seven. These differences are not signifcant.

The weight of eight patients was greater while taking the active drug, and only three were heavier on the placebo; one patient was the same weight on drug and placebo. The other six patients did not have their weight recorded. If these "not recorded" weights can be ignored patients were significantly heavier while taking the active drug $(\mathrm{P}<0.05)$. The average weight gain was $2 \mathrm{lb}$. ( $0.9 \mathrm{~kg}$.) ; individual values ranged from a loss of $4 \mathrm{lb}$. $(1.8 \mathrm{~kg}$.) to a gain of $7 \mathrm{lb}$. $(3.2 \mathrm{~kg}$.).

The preference of patients for either drug was not statistically significant, eight preferring the active drug, four the placebo, and six felt the same on both.

\section{Females with no Menstrual Exacerbation}

There were only seven patients in this group. Four had more headaches on the active drug, two had more on the placebo, and one had the same number in both treatment periods. Four patients suffered longer headaches while on the placebo and three while on the active drug. Four patients had more severe pain while taking the active drug and three had more severe pain while taking the placebo. One patient preferred the active drug, four patients the placebo, and two did not have a preference. The blood pressure of one patient was higher on the active drug, and it was higher in four patients on the placebo. One patient had the same reading on both treatments and in one it.was not recorded. The weight of two patients was raised while taking the active drug, and of two while taking the placebo. One patient had the same weight during both treatments, and the weight was not recorded in two patients. None of these differences was statistically significant.

\section{Side-effects}

Four males experienced side-effects while taking the active preparation, and two while taking the placebo. Drowsiness, dyspepsia, and decreased libido were the main side-effects of the active preparation. In the group of women with menstrually exacerbated migraine 10 experienced side-effects on the active preparation and four on the placebo. Four of this group were postmenopausal and another two were taking an oral contraceptive. Of the remaining 12 five suffered polymenorrhagia while taking the active preparation, one of whom also suffered engorgement of the breasts and varicose veins, and a further patient missed a menstrual period. One woman 
developed erythema nodosum and radiographic evidence of pulmonary sarcoidosis while taking the active preparation. In the group of seven women with no premenstrual exacerbation, three noticed side-effects while taking the active preparation and none with the placebo. Four of this group were menopausal, and one was taking an oral contraceptive. One of the remaining two patients suffered polymenorrhagia while on the active preparation.

In addition, two women had to be withdrawn from the trial while taking the active preparation because of severe polymenorrhagia and nausea in one, and mastitis and a glandularfever-like syndrome in the other. This syndrome consisted of malaise, slight pyrexia, and generalized mild lymphadenopathy. Investigations failed to reveal atypical mononuclear cells in the blood, the Paul-Bunnell test was negative, and the serum alanine aminotransferase was slightly raised, suggesting mild hepatocellular damage. This illness settled about six weeks after stopping the active preparation of flumedroxone.

\section{Discussion}

Flumedroxone produced no benefit in males or in females without menstrual exacerbation of their headaches. In fact the tendency, though not significant, was in the direction of worse results with flumedroxone than with placebo. However, flumedroxone significantly reduced the number and severity of headaches in women whose migraine was particularly bad at the time of menstruation. The magnitude of reduction of headache frequency in this subgroup was not great, and, though more women expressed a preference for the active preparation than for the placebo, the difference did not reach statistical significance. The total duration of the headaches was not significantly affected, and in fact was slightly worse on the active preparation. The headaches tended, therefore, to be rather less frequent and less severe, though longer, in women with menstrual exacerbation while taking flumedroxone.

This finding is in keeping with the known relation between migraine and menstruation, pregnancy, and oral contraception (Mears and Grant, 1962). Whitty et al. (1966) and Phillips (1968) found that headaches tended to be clustered in the days when patients were not taking oral contraceptives-that is, at the time of withdrawal of exogenous progestogen-though Shafey and Scheinberg (1966) were unable to support this conclusion. Flumedroxone may prevent migraine simply by providing a constant blood level of progestogen over the time of menstruation.
With the thirtyfold increase in effective dosage of the progestogen derivative used in the present trial compared with that in our earlier trial (Hudgson et al., 1967a) we encountered a higher frequency of side-effects. Six of the 14 women of reproductive ages suffered polymenorrhagia, and a further two had to be withdrawn from the trial because of severe polymenorrhagia in one case and mastitis and a glandular-feverlike syndrome in the other. It is impossible at present to say whether this syndrome or the sarcoidosis which developed in another woman, both while taking the active preparation, were caused by the flumedroxone.

The fact that half the group of patients who benefited from flumedroxone developed polymenorrhagia markedly limits its usefulness as a prophylactic agent against migraine. Methysergide has two main dangers-the relatively slight risk of retroperitoneal fibrosis and the rather more worrying vasoconstrictor action in patients with asymptomatic degenerative vascular disease. At present it appears that there is no satisfactory prophylactic agent for patients with very frequent migrainous headaches, and most clinicians will continue to fall back on tranquillizers as the mainstay in treatment of these difficult patients.

The Demigran and placebo tablets used in this trial were prepared and supplied by Leo Laboratories Limited. We wish to thank Dr. J. N. Walton for permission to study those patients included who were under his care, and Mr. W. T. Wing, the hospital group pharmacist, for his continued help with the extra work placed on his department, We are also grateful to Mrs. D. Weightman for statistical assistance.

\section{REFERENCES}

Hudgson, P., Foster, J. B., and Newell, D. J. (1967a). Brit. med. 3., 2 91.

Hudgson, P., Foster, J. B., and Walton, J. N. (1967b). Lancet, 1, 444. Hudgson, P. Foster, J. B., and Walton, J. N. (1967c). Amer. Heart \%., 74,854 .

Lundberg, P. O. (1965). Opusc. med. (Stockh.), 10, 59.

Mears, E., and Grant E. C. G. (1962). Brit. med. Y., 2, 75.

Phillips, B. M (1968). Brit. med. I., $2,99$.

Schwartz, F. D., Dunea, G., and Kark, R. M. (1966). Amer. Heart J. 72,843 .

Shafey, S., and Scheinberg, P. (1966). Ann. intern. Med., 65, 863.

Sørensen, B. (1964). Unpublished observations.

Southwell, N., Williams, J. D., and Mackenzie, I. (1964). Lancet, 1, 523.

Whewell, J. (1966). Brit. med. 3., 2, 394.

Whitty, C. W. M., Hockaday, J. M., and Whitty, M. M. (1966). Lancet, 